and 16 weeks respectively. Five patients received cytosine arabinoside and C.S.F. relapse occurred at 3, 3, 3, 4, and 14 weeks respectively. Thus in this small trial neither agent appears to be superior with regard to remission duration, and the larger volume of diluent did not seem to favourably affect the outcome of these patients compared with our previous experience using a small volume of diluent.

\section{References}

Clifford, P., Singh, S., Stjernsward, J., and Klein, G. (1967). Cancer Research, $27,2758$.

Cooper, E. H., Hughes, D. T., and Topping, N. E. (1966). British fournal of Cancer, 20, 102 .

Frank, G. L. (1968). In Cancer in Africa, ed. P. Clifford, C. A. Linsell, and G. L. Timms. p. 251. Nairobi, East African Publishing House.
Iversen, U., Iversen, O. H., Ziegler, J. L., and Bluming, A. Z. (1971). To be published.

Rall, D. P. (1965). Cancer Research, 25, 1572.

Rall, D. P., Reiselbach, R. E., Oliverio, V. T., and Morse, E. E. (1962). Cancer Chemotherapy Reports, 16, 185.

Reiselbach, R. E., Di Chiro, G., Freireich, E. J., and Rall, D. P. (1962). New England fournal of Medicine, 267, 1273.

Reiselbach, R. E., Morse, E. E., Rall, D. P., Frei, E., and Freireich, E. J. (1963). Archives of Internal Medicine, 111, 620.

Rubin, R. C., Ommaya, A. K., Henderson, E. S., Bering, E. A., and Rall, D. P. (1966). Neurology, 16, 680.

Steel, R. T., Yankee, R. A., and Henderson, E. S. (1965). Fournal of the American Medical Association, 205, 863.

Sullivan, M. P., et al. (1969). Blood, 34, 301.
Thomas, L. B. (1965). Cancer Research, 9, 1555.

Wang, J. J., and Pratt, C. B. (1970). Cancer, 25, 531

Ziegler, J. L., Bluming, A. Z., Morrow, R. H., Fass, L., and Carbone, P. P. (1970a). Blood, 36, 718.

Ziegler, J. L., Morrow, R. H., Fass, L., Kyalwazi, S. K., and Carbone, P. P. (1970b). Cancer, 26, 94.

\title{
Leakage of Oxygen from Blood and Water Samples Stored in Plastic and Glass Syringes
}

\author{
PETER V. SCOTT， J. N. HORTON，W. W. MAPLESON
}

British Medical fournal, 1971, 3, 512-516

\section{Summary}

Theory and experiment showed that samples of blood and water stored in $2-\mathrm{ml}$ and $5-\mathrm{ml}$ syringes made of polypropylene, polystyrene, or S.A.N. co-polymer exchanged oxygen with their surroundings. In the first hour the exchange was due mainly to equilibration with the plastic of the syringe and only in small degree to permeation through the plastic. With high initial tension or with blood of low haemoglobin concentration the exchange can result in errors in $\mathrm{PO}_{2}$ of up to $6 \%$ in two minutes and $16 \%$ in 30 to 60 minutes. With all-glass syringes the exchange was much slower but, even so, after 24 hours was important in all but a few of 18 interchangeable glass syringes. Therefore unless analysis can be started immediately all-glass syringes are to be preferred, and for prolonged storage even these should be selected.

\section{Introduction}

A fall of oxygen tension in stored blood samples due to metabolism is well recognized. Reports of additional changes in oxygen tension in both blood and water samples stored in plastic syringes are conflicting (Laver and Seifen, 1965; Fletcher and Barber, 1966; Adams et al., 1967), but the work of Hilty and Karendal (1969) leaves no doubt that in some circumstances these additional changes are important. This paper describes work designed to elucidate the mechanism of the changes and to show in what circumstances they are of importance and whether they can be avoided by the use of allglass syringes.

Welsh National School of Medicine, Cardiff CF4 4XN

PETER V. SCOTT, M.B., F.F.A. R.c.s., Lecturer, Department of Anaesthetic W. W. MAPLESON, PH.D., F.INST.P., Reader in the Physics of Anaesthesia

University Hospital of Wales, Cardiff CF4 4XW

J. N. HORTON, M.B., F.F.A. R.c.s., Consultant Anaesthetist

\begin{abstract}
Materials and Methods
Oxygen tension was measured with a Radiometer E5046 polarographic oxygen electrode fitted with a $20-\mu \mathrm{m}$ polypropylene membrane and provided with a digital display of the output current. Zero and sensitivity of the electrode were checked often enough to be able to correct for the small amount of drift which occurred during the experiments. The response of this electrode is linear though the response time may vary. Corrections for incompleteness of response were applied to all measurements (Mapleson et al., 1970).

Sterile distilled water or heparinized fresh blood was equilibrated in bubble tonometers with oxygen at the tension under investigation for one hour at $37^{\circ} \mathrm{C}$. The tonometers were sterilized before use in chlorhexidine $1 / 5,000$ to avoid any oxygen consumption by contaminant bacteria. Gas mixtures of known, constant composition were obtained from Wosthoff pumps; mixtures perfusing blood always contained 5\% carbon dioxide. The $\mathrm{pH}$ and haemoglobin concentration of the blood were determined at the close of each experiment.

Bubble-free samples of water or blood were taken into dry syringes of 2- or 5-ml capacity and aliquots analysed for $\mathrm{Po}_{2}$ at various time intervals. Between analyses the syringes were sealed with metal or plastic caps and usually stored on the laboratory bench at room temperature. Six makes of commonly used plastic syringe and a single make of interchangeable "all-glass" syringe were investigated. During blood experiments a glass syringe was used as a control to estimate and correct for oxygen consumption by leucocytes (Asmussen and Nielsen, 1961; Hedley-White and Laver, 1964). All experiments were performed by one investigator.
\end{abstract}

\section{Results}

The fall in oxygen tension in water during storage in six different brands of $5-\mathrm{ml}$ plastic syringe and one $5-\mathrm{ml}$ glass syringe is shown in Fig. 1. The water was initially in equilibrium with $96 \% \mathrm{O}_{2}$ and, for comparison with other experiments, the fall in tension is expressed as a percentage of the difference between the initial tension in the water and the oxygen tension in the ambient air. Clearly the fall is considerable for all the plastic syringes and small for the glass syringe. 
The corresponding rise in tension when the water was initially in equilibrium with $0 \%$ oxygen is shown in Fig. 2. A fresh sample of each of the same six brands of syringe was used. The order of merit is similar but not identical. The average rise in tension is somewhat greater, in the terms in which it is expressed, than the corresponding fall in Fig. 1.

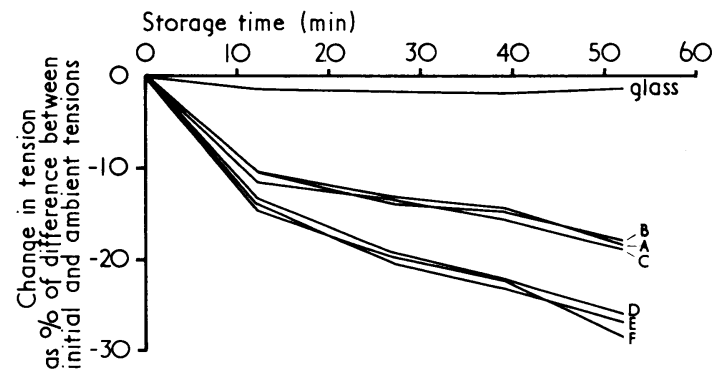

FIG. 1-Fall in oxygen tension during storage of water, initially equilibrated with $96 \%$ oxygen, in $5-\mathrm{ml}$ syringes of S.A.N. co-polymer (A); polypropylene $(B, C)$; and polystyrene $(D, E, F)$.

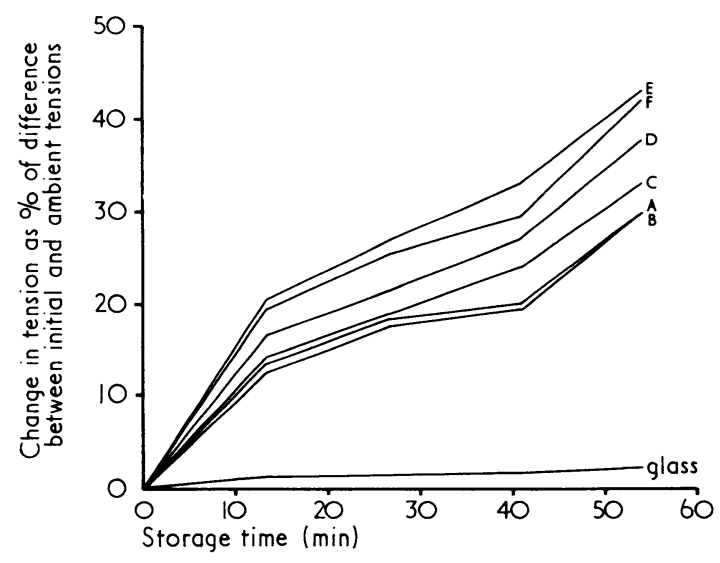

FIG. 2-Rise in oxygen tension during storage of water, initially equilibrated with $0 \%$ oxygen, in $5-\mathrm{ml}$ syringes.

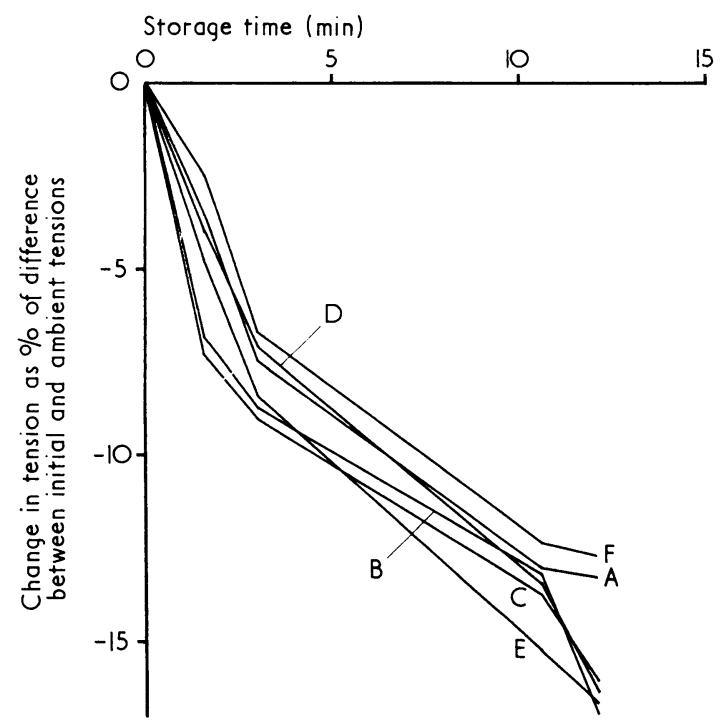

FIG. 3-Fall in oxygen tension during the first few minutes of storage of water, initially equilibrated with $100 \%$ oxygen, in 5 -ml syringes.
Fig. 1 shows a clear difference between polystyrene on the one hand and polypropylene and S.A.N. co-polymer on the other. In Fig. 2 the difference is again present, though less clear cut. Fig. 3 shows, on an enlarged scale, the fall in tension during the first few minutes of storage. For this experiment the water was initially equilibrated with $100 \%$ oxygen and then stored in a third sample of each of the six brands of syringe. The onset of loss is clearly very rapid but the differences between plastics do not become clear during this period.

Storage of the syringes in a refrigerator at $4^{\circ} \mathrm{C}$ instead of at room temperature resulted in a slower fall, from a high initial tension, over a 12-minute period. Loss from 2-ml syringes was of about the same magnitude as that from $5-\mathrm{ml}$ syringes. There was no difference between the use of plastic and metal caps during storage.

Water, initially equilibrated with $100 \%$ oxygen, was stored in 2-ml interchangeable all-glass syringes for 24 hours at room temperature. One syringe with a clearly visible crack showed a fall in oxygen tension of $72 \%$ of the difference from ambient tension. In 17 others, all apparently sound, the fall ranged from 1.3 to $39.3 \%$, with a mean of $14.8 \%$.

In three experiments samples of blood were stored for $11 \frac{1}{2}$ minutes in six 5-ml plastic syringes (two samples in each) and in one $5-\mathrm{ml}$ glass syringe (seven samples). The changes in tension in the blood in the plastic syringes (expressed as a difference from the change in tension in the glass syringe) are listed in Table I.

\section{Theory}

From the permeability of polystyrene and polypropylene to oxygen (Selby, 1961; Major and Kammermeyer, 1962) and from the dimensions of a 5-ml syringe it can be calculated that, for the circumstances of Figs. 1 and 3, permeability would account for a loss of only about $0.1 \%$ per minute, whereas the graphs show observed losses of $5 \%$ per minute initially, falling to $0.2 \%$ per minute. Conversely, from estimates of the solubility of gases in various plastics (G.S. Park, personal communication) and knowing that in a full $5-\mathrm{ml}$ syringe about $2.5 \mathrm{~cm}^{3}$ of plastic is in contact with the sample, it was estimated that equilibration of oxygen between sample and syringe could well account for most of the fall in tension in Fig. 1. Thus it seems that the sample equilibrates first with the plastic by solution, and only later with the ambient atmosphere by permeation.

This mechanism was confirmed experimentally by suspending one syringe of each brand in a stream of oxygen overnight to allow the plastic to equilibrate fully with the gas. The syringes were then filled with water equilibrated with $100 \%$ oxygen. After storage in air the oxygen content of the water rose in all syringes, and in all but one was higher after 48 minutes than it

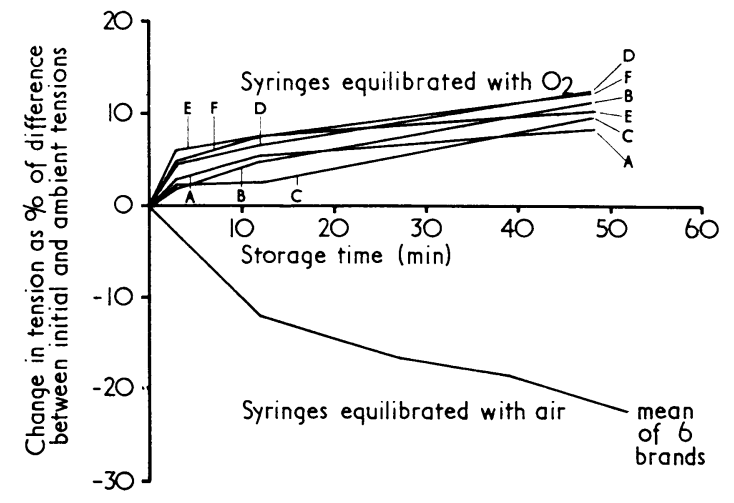

FIG. 4-Effect on the change in oxygen tension during storage of water, initially equilibrated with $100 \%$ or $96 \%$ oxygen, of pre-equilibration of $5-\mathrm{ml}$ plastic syringes with oxygen or air. 
was after 0,3 , or 12 minutes (Fig. 4). The mechanism suggests that any exchange of oxygen will be proportional to the difference between the initial tension in the sample and the initial tension in the plastic-almost invariably that of ambient air. If so, the percentage fall of tension in Fig. 1 should, on average, be equal to the percentage rise in Fig. 2. In fact, the rise is somewhat greater. This is because the water in the syringe cools during storage, the solubility of oxygen in the water therefore increases, and the tension of oxygen in the water therefore falls, independently of any exchange.

This temperature effect was taken into account by calculating a "corrected" initial tension. This was the tension that would have existed in the water if it had cooled immediately to the mean* of its actual temperature during the storage period. An "exchange factor" was then calculated for each point in Figs. 1-3. This exchange factor is the exchange of oxygen $(\mathrm{ml} / 100 \mathrm{ml})$ which has occurred by any given time divided by the difference $(\mathrm{mm} \mathrm{Hg}$ ) between the corrected initial tension in the water and the initial tension in the syringe.

Fig. 5 shows the mean exchange factor for the six brands for each period of storage under each condition. The discrepancy between Figs. 1 and 2 has largely disappeared and what remains is unimportant for the present purposes. Similarly the slower fall in a high initial tension when samples were stored at $4^{\circ} \mathrm{C}$ can be quantitatively attributed to the change of tension with temperature. It does not indicate any significant alteration of exchange factor.

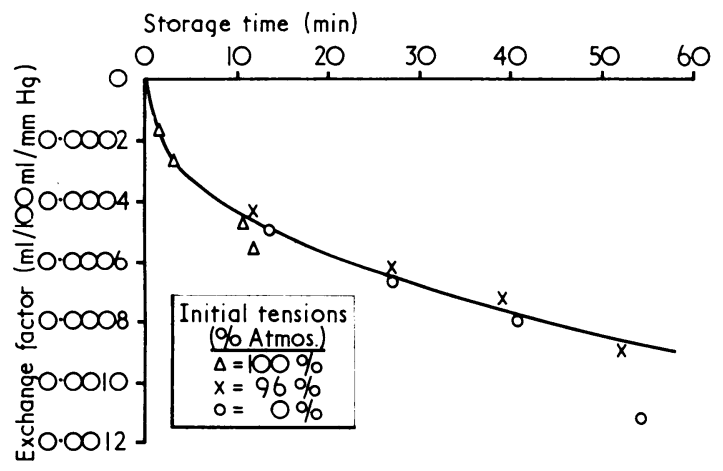

FIG. 5-Mean oxygen "exchange factor" for six brands of plastic syringe for various storage times and initial tensions. Data for plotted points from Figs. 1-3.

As aliquots are expelled from a syringe the ratio of surface area available for exchange to the volume of sample remaining gradually increases. Therefore, when a syringe is nearly empty, as it was with the last aliquots of all experiments incorporated in Fig. 5, the exchange factor should be greater than for a full syringe. This would be so even if oxygen were insoluble in the plunger. Allowing for this, the free-hand curve drawn in Fig. 5 should represent the exchange factor to be expected for full $5-\mathrm{ml}$, and even approximately for full $2-\mathrm{ml}$ or $10-\mathrm{ml}$ syringes of any of the plastics studied.

This information was used in a computer programme to predict tension changes to be expected with blood samples

*This mean temperature was estimated from an equation based on measurements of the cooling in air of water stored in $5-\mathrm{ml}$ syringes (three plastic and one glass):

$$
T_{m}=\left[T_{w}-0.23\left(T_{w}-T_{s}\right)-T_{a}\right]\left[1-e^{-t / 12.5}\right] 12 \cdot 5 / t+T_{a}
$$

where $T_{m}=$ mean water temperature over the time $t$ (in minutes), $T_{w}=$ initial water temperature, $\mathrm{T}_{\mathbf{s}}=$ initial syringe temperature, and $\mathrm{T}_{\mathrm{a}}=$ ambient temperature during storage. under a variety of conditions. The programme incorporated Kelman's (1966) subroutine for the oxyhaemoglobin dissociation curve and a procedure for calculating the change of tension produced by anaerobic temperature change, based on the approach of Severinghaus (1966) but using the data of Kelman and Nunn (1968). The programme input consisted of the initial oxygen tension of the syringe material, the exchange factor, and various characteristics of the blood- $\mathrm{pH}$, haemoglobin concentration, initial oxygen tension, initial temperature, and mean storage temperature. The programme then calculated the initial saturation and content, the corrected initial tension difference, the consequent loss of content, and the final tension and saturation after rewarming to the initial temperature.

The programme was also run for the conditions of the three blood experiments, a mean exchange factor having been determined experimentally for the particular set of syringes and storage times used in each experiment. The calculated changes of tension were in reasonable agreement with the observed changes (Table I).

TABLE I-Experimental and Computed Changes in Oxygen Tension (Additional to those due to Metabolism) in Fresh Blood Stored at Room Temperature for $11 \frac{1}{2}$ minutes in 5-ml Brand D Plastic Syringes. Initial Blood Temperature $37^{\circ} \mathrm{C}$

\begin{tabular}{|c|c|c|c|}
\hline \multirow{2}{*}{\multicolumn{2}{|c|}{$\begin{array}{l}\text { Initial Tension } \\
\text { of Blood ( } \mathrm{mm} \mathrm{Hg} \text { ) }\end{array}$}} & \multicolumn{2}{|c|}{$\begin{array}{c}\text { Change in Tension (mm Hg) } \\
\text { (Mean } \pm 95 \% \text { Confidence Limits) }\end{array}$} \\
\hline & & Experimental & Computed \\
\hline $\begin{array}{r}680 \ldots \\
102 \ldots \\
68 . .\end{array}$ & $\begin{array}{l}. . \\
\cdots\end{array}$ & $\begin{array}{cc}-68 \pm & 10 \\
0.4 \pm 2 \cdot 0 \\
0.0 \pm 1 \cdot 1\end{array}$ & $\begin{array}{rl}-59 & \pm 12 \\
2.9 & 0.6 \\
0.7 & \pm .2\end{array}$ \\
\hline
\end{tabular}

\section{Discussion}

\section{MECHANISM OF CHANGE}

In showing considerable change of oxygen tension in liquid samples stored in plastic syringes our results are in general agreement with those of Fletcher and Barber (1966) and Hilty and Karendal (1969). These changes of tension can occur in various ways, such as (1) oxygen consumption by leucocytes in fresh blood (Asmussen and Nielsen, 1961); (2) equilibration with existing syringe contents, such as heparin (Berggren, 1942; Charlton et al., 1963; Fletcher and Barber, 1966); (3) oxygen consumption in the presence of metal-for example, syringe plunger, mercury (Wiesinger, 1950; Hilty and Karendal, 1969); (4) diffusion of oxygen at the nozzle of the syringe (Fletcher and Barber, 1966); (5) diffusion of oxygen through the walls of a plastic syringe and between plunger and barrel of a glass syringe; and (6) solution of oxygen in the walls and plunger of a plastic syringe. The first four mechanisms were virtually eliminated from our work either by the design of the experiment or by applying a correction factor.

Thus it is evident from our experiments and theory that with plastic syringes the sixth factor is initially the principal one for oxygen exchange. The same conclusion was reached by Le Blanc and Johnson (1971) for the loss of xenon-133 from saline in plastic syringes. Hilty and Karendal (1969) do not mention this mechanism of loss but it probably explains their finding that "repeated use [of plastic syringes] appeared to reduce the oxygen diffusing capacity." When the repeated use was with samples at the same tension the plastic would gradually equilibrate with the sample tension, causing less change of tension in the later samples.

In our experiments with glass syringes the principal cause of continuing loss would be diffusion between barrel and plunger or through cracks in the glass. Even apart from the one very large loss through a visible crack, we observed much greater exchange than did Fletcher and Barber (1966) or Hilty and Karendal (1969). It may be significant that Hilty and Karendal specify that they used non-interchangeable syringes, whereas 
ours were interchangeable and would therefore presumably include a wider range of clearances between barrel and plunger. Additionally, since we did not scrupulously inspect our glass syringes, some of them may have had minute cracks. Whatever the explanation, it is evident that for prolonged storage and for the highest accuracy only selected all-glass syringes should be used.

\section{COMPUTED MAGNITUDES OF CHANGE}

Our experimental results indicate a somewhat greater exchange with polystyrene than with polypropylene or with S.A.N. co-polymer (Figs. 1 and 2). A hierarchical analysis of variance showed that this difference in exchange was highly significant statistically $(P<0.000005)$. The difference, however, is of doubtful clinical significance, so for computing typical changes exchange factors were read from the representative curve of Fig. 5. Table II shows the resultant computed changes of oxygen tension of blood stored in plastic syringes under a range of conditions. In all circumstances the syringe is assumed to be in equilibrium with ambient air at the start.

TABLE II-Computed Oxygen Exchange of Blood Stored in Plastic Syringes

\begin{tabular}{|c|c|c|c|c|c|c|}
\hline & \multirow{2}{*}{$\begin{array}{c}\text { Storage } \\
\text { Time } \\
(\mathrm{min})\end{array}$} & \multirow{2}{*}{$\begin{array}{c}\text { Initial } \\
\text { Tension } \\
(\mathrm{mm} \mathrm{Hg})\end{array}$} & & \multicolumn{2}{|c|}{ Change of Tension } & \multirow{2}{*}{$\begin{array}{c}\text { Change } \\
\text { of } \\
\text { content } \\
\text { (") } \\
\text { Initial) }\end{array}$} \\
\hline & & & & $\stackrel{(\mathrm{mm}}{\mathrm{Hg})}$ & $\begin{array}{c}(\% \\
\text { Initial })\end{array}$ & \\
\hline $\begin{array}{l}\text { "Normal" } \\
\text { conditions }\end{array}$ & $30-60$ & $\begin{array}{r}650 \\
300 \\
100 \\
33\end{array}$ & & $\begin{array}{r}-106.3 \\
-21.3 \\
5.8 \\
0.3\end{array}$ & $\begin{array}{r}-16.4 \\
-7.1 \\
5.8 \\
0.9\end{array}$ & $\begin{array}{r}-1.4 \\
-0.3 \\
0.4 \\
0.9\end{array}$ \\
\hline Effect of storage time & 2 & 650 & & $-30 \cdot 3$ & $-4 \cdot 7$ & -0.4 \\
\hline $\begin{array}{l}\text { Effect of ambient } \\
\text { temp. during storage } \\
\text { (Ta) }\end{array}$ & $30-60$ & $\begin{array}{l}650 \\
650 \\
100 \\
100\end{array}$ & $\begin{array}{r}1 \mathrm{a} \\
37 \\
4 \\
37 \\
4\end{array}$ & $\begin{array}{r}-129.1 \\
-83.3 \\
3.3 \\
7.6\end{array}$ & $\begin{array}{r}-19 \cdot 9 \\
-12 \cdot 8 \\
3 \cdot 3 \\
7 \cdot 6\end{array}$ & $\begin{array}{r}-1.7 \\
-1.1 \\
0.2 \\
0.5\end{array}$ \\
\hline Effect of $\mathrm{Hb}$ & $30-60\{$ & $\begin{array}{l}650 \\
650 \\
100 \\
100\end{array}$ & $\begin{array}{l}\mathrm{Hb} \\
15 \\
5 \\
15 \\
5\end{array}$ & $\begin{array}{r}-106.3 \\
-107.5 \\
5 \cdot 8 \\
12.7\end{array}$ & $\begin{array}{r}-16.4 \\
-16.5 \\
5.8 \\
12.7\end{array}$ & $\begin{array}{r}-1.4 \\
-3.6 \\
0.4 \\
1.1\end{array}$ \\
\hline Effect of $\mathrm{pH}$ & $30-60$ & 300\{ & $\begin{array}{c}\mathrm{pH} \\
7 \cdot 7 \\
6.8\end{array}$ & $\begin{array}{l}-24 \cdot 3 \\
-10 \cdot 8\end{array}$ & $\begin{array}{l}-8 \cdot 1 \\
-3 \cdot 6\end{array}$ & $\begin{array}{l}-0.4 \\
-0.2\end{array}$ \\
\hline $\begin{array}{l}\text { Effect of barometric } \\
\text { pressure }(\mathrm{Pb})\end{array}$ & $30-60$ & 100\{ & $\begin{array}{c}\mathrm{Pb} \\
780 \\
710 \\
600\end{array}$ & $\begin{array}{l}6 \cdot 1 \\
5 \cdot 2 \\
3 \cdot 7\end{array}$ & $\begin{array}{l}6 \cdot 1 \\
5 \cdot 2 \\
3 \cdot 7\end{array}$ & $\begin{array}{l}0.4 \\
0 \cdot 3 \\
0 \cdot 2\end{array}$ \\
\hline
\end{tabular}

Syringes: $5 \mathrm{ml}$ or $2 \mathrm{ml}$, initially in equilibrium with ambient air.

Exchange factor: $8 \times 10^{-5}(\mathrm{ml} / 100 \mathrm{ml}) / \mathrm{mm} \mathrm{Hg}$ for $30-60$ minutes storage and $2 \times 10^{-4}$ for 2 minutes.

Normal conditions: $\mathrm{Hb}=15 \mathrm{~g} / 100 \mathrm{ml}, \mathrm{pH}=7 \cdot 4, \mathrm{~Pb}=760 \mathrm{~mm} \mathrm{Hg}$, initial blood temp. $=37^{\circ} \mathrm{C}$, ambient temp. $=22 \cdot 5^{\circ} \mathrm{C}$.

In day-to-day clinical work arterial tensions are usually below $300 \mathrm{~mm} \mathrm{Hg}$ and it is debatable whether the errors of up to $7 \%$ in tension would influence clinical management. However, in research work, and even in some clinical situations, the errors may be of considerable importance. Changes of content are always quite small but could lead to errors of up to $6 \%$ in the calculation of cardiac output and $6 \%$ of the cardiac output in the calculation of shunt. Errors can be reduced by limiting the storage time but, since about a quarter of the above losses occur within two minutes, storage must be restricted to seconds rather than minutes for the highest accuracy.

When samples are to be stored for more than a few minutes it is usual to chill them to reduce oxygen consumption. Table II shows that in samples with high initial tension the fall will be reduced but in samples with low initial tension the rise will be increased. The effect can be clearly seen in the experimental results of Hilty and Karendal, though no comment is made in their text. The explanation lies in the fall in tension with fall in blood temperature.
With low haemoglobin concentration large changes of tension occur even with low initial tension. For example, for blood from a patient in chronic renal failure with a haemoglobin concentration of $5 \mathrm{~g} / 100 \mathrm{ml}$ and a normal $\mathrm{PaO}_{2}$ the errors would be almost as large as those for blood at a very high $\mathrm{PaO}_{2}$ for a normal patient.

The $\mathrm{pH}$ has only a small effect on change of content but considerably affects the change of tension in two ways-firstly, by affecting the change of tension with temperature and hence affecting the tension gradient during storage, and, secondly, by altering the shape of the dissociation curve. These effects indicate the impracticability of correcting for exchange in blood samples.

By its influence on ambient oxygen tension barometric pressure has an effect on exchange. However, the effect is small even for a change from $780 \mathrm{~mm} \mathrm{Hg}$ (fair weather at sea level) to $600 \mathrm{~mm} \mathrm{Hg}$ (bad weather at $5,000 \mathrm{ft} ; 1,520 \mathrm{~m}$ ).

Changes of saturation are always small and become appreciable only at low haemoglobin concentration and low initial tension. For example, blood of $5 \mathrm{~g} / 100 \mathrm{ml}$ haemoglobin, $\mathrm{pH} 7 \cdot 4$, initially at a $\mathrm{Po}_{2}$ of $33 \mathrm{~mm} \mathrm{Hg}$, stored for 30-60 minutes at room temperature shows a rise of $1.6 \%$ in saturation.

In general, the solubility and permeability of oxygen in various types of nylon is much less than it is for the plastics studied, so that on theoretical grounds nylon syringes could be expected to perform much better than the other plastic ones, though probably not so well as glass. Nylon syringes cost about 10 times as much as other plastic syringes and about half as much as glass.

\section{CARBON DIOXIDE}

We have made no measurements of $\mathrm{CO}_{2}$ tension but the exchange of gas can be estimated theoretically. Carbon dioxide is up to eight times as permeable as oxygen in plastic (Selby, 1961; Major and Kammermeyer, 1962) and perhaps up to 30 times as soluble (G.S. Park, personal communication) but it is effectively much more soluble in blood (except in comparison with oxygen at tensions on the steep part of the oxyhaemoglobin dissociation curve). From these properties it can be estimated that storage of blood samples in plastic syringes will cause errors in measured $\mathrm{PCO}_{2}$ which are smaller than the worst errors for $\mathrm{PO}_{2}$ but are not negligible. The errors could probably be ignored in clinical practice but might be important in research.

\section{Conclusions}

Plastic syringes may be satisfactory for handling blood samples even in precise work, but only if injection into the electrode takes place within a few seconds of sampling. Even to have the electrode in a nearby room may lead to delays of a minute or two, and with high initial tension this could cause errors of $5 \%$ in oxygen tension and $2 \%$ in calculated cardiac output or shunt. For most day-to-day clinical purposes storage of up to an hour in plastic syringes may be acceptable except for samples of very high initial tension or low haemoglobin concentration, when errors of up to $16 \%$ in oxygen tension and $6 \%$ in cardiac output and shunt can occur. Because of all the variables involved, it is impracticable under clinical conditions to correct for the errors introduced by storing samples in plastic syringes. In view of this and because of the many other sources of error inherent in measuring oxygen tension it may be desirable, even for routine clinical work, to use all-glass syringes. For the highest precision or for prolonged storage even the glass syringes should be carefully selected.

We are grateful to Professor William W. Mushin for constant encouragement; to Dr. G. S. Park, of the University of Wales 
Institute of Science and Technology, for advice and data on the properties of plastics; and to Mr. E. K. Hillard for preparing the illustrations. We gratefully acknowledge the supply of samples of their plastic syringes from Messrs. Becton Dickinson, Gillette, Johnson and Johnson, Sherwood Medical Industries, Smith and Nephew-Southalls, and Steriseal.

\section{References}

Adams, A. P., Morgan-Hughes, J. O., and Sykes, M. K. (1967). Anaesthesia,

Asmussen, E., and Nielsen, M. (1961). Scandinavian fournal of Clinical and Laboratory Investigation, 13, 297.

Berggren, S. M. (1942). Acta Physiologica Scandinavica, 4, Suppl. No. 11,

p. 51.
Charlton, G., Read, D., and Read, J. (1963). Fournal of Applied Physiology, $18,1247$.
Fletcher, G., and Barber, J. L. (1966). Fournal of Applied Physiology, 21, 463. Hedley-White, J., and Laver, M. B. (1964). Journal of Applied Physiology, 19,901 .

Hilty, H., and Karendal, B. (1969). Acta Societatis Medicorum Upsaliensis, 74, 193.

Kelman, G. R. (1966). Journal of Applied Physiology, 21, 1375.

Kelman, G. R., and Nunn, J. F. (1968). Computer Produced Physiological Tables. London, Butterworths.

Laver, M. B., and Seifen, A. (1965). Anesthesiology, 26, 73.

Le Blanc, A. D., and Johnson, P. C. (1971). Physics in Medicine and Biology, 16, 105.

Major, C. J., and Kammermeyer, K. (1962). Modern Plastics, 39, 135.

Mapleson, W. W., Horton, J. N., Ng, W. S., and Imrie, D. D. (1970) Medical and Biological Engineering, 8, 585 .

Selby, J. W. (1961). In Modern Food Packaging Film Technology, p. 55 Leatherhead, British Food Manufacturing Industries Research Association.

Severinghaus, J. W. (1966). Fournal of Applied Physiology, 21, 1108.

Wiesinger, K. (1950). Die Polarographische Messung der Sauerstoffspannung des Blutes, p. 51. Basel, Benno Schwabe.

\title{
${ }^{131}$ I Hippuran Renogram in Acute Renal Failure
}

\author{
M. E. MAYO, \\ P. J. HILTON, \\ N. F. JONES, \\ R. W. LLOYD-DAVIES, \\ D. N. CROFT
}

British Medical fournal, 1971, 3, 516-517

\section{Summary}

A hippuran renogram pattern of the type usually interpreted as indicating urinary tract obstruction was seen in acute tubular necrosis and was present both in the oliguric and in the diuretic phase. It seems that in acute renal failure the renogram does not distinguish urinary tract obstruction from intrinsic renal disease.

\section{Introduction}

It is sometimes difficult to decide whether oliguric renal failure is due to urinary tract obstruction or to intrinsic renal disease. The hippuran renogram shows a characteristic pattern in urinary obstruction, and Fig. 1 (a) is the renogram of a patient with acute obstruction at the lower end of both ureters. Various reports (Winter, 1961; Trinkle and Kiser, 1964) have indicated that in oliguric renal failure the renogram could distinguish obstruction from intrinsic renal disease, but our experience has shown that it can be misleading.

\section{Case Reports}

Case 1.-A man aged 66 developed acute tubular necrosis due to hypotension following rupture of an abdominal aortic aneurysm and subsequent surgery. The renogram (Fig. 2) was obtained on the fourth day after the onset of oliguria and showed an "obstructed" pattern. He died 12 days after admission and urinary tract obstruction was not found at necropsy.

Case 2.-A man of 37 developed acute renal failure complicating pneumonia. Renal biopsy was compatible with acute tubular necrosis and he recovered normal renal function. The first renogram was performed when urine flow had risen to over $21 . /$ day and also showed an "obstructed" pattern (Fig. 3). Ureterograms obtained the next day were normal. Five weeks later the pattern of the renogram had not changed, and at this time the

blood urea was $47 \mathrm{mg} / 100 \mathrm{ml}$ and an intravenous pyelogram was normal.
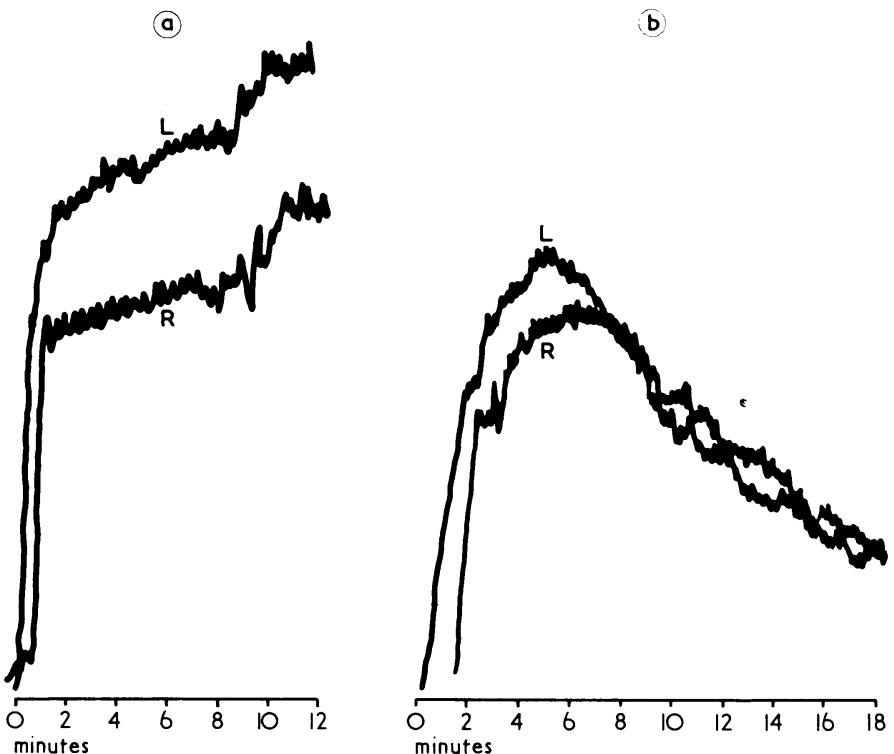

FIG. 1-Hippuran renograms of a woman aged 28 (a) during oliguric renal failure due to bilateral ureteric obstruction following caesarean section; she was receiving peritoneal dialysis at the time; and (b) after reconstructive surgery.

Case 3.-A man of 76 developed Gram-negative septicaemia secondary to urinary tract infection and bladder neck obstruction. He was oliguric for a week but recovered without dialysis. Serial renograms were obtained, the first during the oliguric phase, the second and third (Fig. 4) during recovery of renal function, and all three showed an "obstructed" pattern. An intravenous pyelogram three weeks after admission showed no upper urinary tract obstruction, and the third segment of the renogram had returned to normal by the fifth week. It should be noted that the bladder neck obstruction was not sufficient to produce secondary changes in the upper urinary tract.

Case 4.-A man of 59 was admitted to hospital with a swollen, hard, and tender left calf. Despite the presence of distal pulses it was thought that he had acute ischaemia of the calf muscles and this leg was explored. When the deep fascia was released oedematous pale muscle bulged out and regained its normal colour in five minutes. The next day he was found to be 